\title{
ESL teachers' perceptions and practices of code-switching in a Malaysian Chinese independent secondary school
}

\author{
Wong Yee Von \\ yeevonwong@gmail.com \\ University of Selangor, Malaysia \\ David Yoong \\ davidyoong@um.edu.my \\ University of Malaya, Malaysia
}

\begin{abstract}
Code-switching (CS) is one of the communicative strategies used in defining and structuring social relationships of speakers. In this study, we demonstrate how teachers perceive and employ CS in a Malaysian Chinese Independent School (MCIS) English classrooms to achieve communicative intents and to create a sense of belonging among students. Ethnography recording of classroom discourse and semi-structured interviews with seven English teachers were employed. The analysis reveals a noteworthy commitment that CS does not only act as a pedagogical tool but also as a means of facilitating interpersonal communication in class.
\end{abstract}

Keywords: Malaysian Chinese Secondary School, Classroom Code-switching

\section{Introduction}

Code-switching (CS) is a linguistic phenomenon where speakers switch one register (including languages) to another in an interaction. Contrary to the perception that CS is evidence of deficient language proficiency in bilingual speakers, educationists like Kuang and David (2015), and Reyes (2004) suggest CS is natural in bilingual conversations. It serves as a device to assist interlocutors 
in achieving communicative goals. For instance, Ahmad and Jusoff's (2009) study of 299 college students in a Level 1 English communication proficiency class shows that the CS amongst Malaysian college instructors was associated with their students' learning accomplishments. When asked, the majority of the students say that CS is utilised by their instructors to facilitate certain actions, like checking for comprehension, clarifying new vocabulary, and overseeing classroom exercises. CS is often used to mark social identities and relationships. CS creates etymological solidarity, particularly between individuals who share a similar ethnocultural personality (Sert, 2005). Similarly, Crystal (2006) states that a speaker's change from the majority dialect to the minority one communicates solidarity with the minority group.

Within the Malaysia Chinese Independent School (MCIS) context, this indexical link between the language choice of teachers and pedagogical practice is especially prevalent. Because the primary level students had very little exposure to English, teachers employ the students' native language to engage them and to facilitate learning (Yao, 2011). In MCIS, the Chinese language is the medium of instruction. English, on the other hand, is also taught to enable students to communicate nationally and internationally. The use of CS in the MCIS ESL classroom does not merely establish a means of accomplishing pedagogical goals, but also to signal a sense of belonging. For instance, one of the teacher respondents in this research points out:

"Because we are in Chinese school, they feel like (.) If they feel like you know their language, you have a certain connection to them(.) they will feel more connected to you and they will be more accepting of you."

[Teacher 3]

This teacher's interpretation of CS reveals the existence of group membership norms and presuppositions of language identities. CS can be a conscious strategy of constructing identity (Thomas \& Wareing, 2000). In the Malaysian context, Dumanig and David (2011) suggest that CS are used "not because [people] have to, but because they want to", indicating that CS serves with a clear intended purpose. Additionally, How et al.'s (2015) study on the perceptions of language vitality among primary vernacular school students in Malaysia discovered the frequent use of Mandarin and Tamil in many contexts. The findings suggest that students have been enculturated from young to use their mother tongue more than the other languages. The present 
study explores how Chinese ESL teachers use CS in classes to teach Chinese students who are not quite competent in the English language, and it is driven by the following research questions:

i. What perception do ESL teachers have about the use of CS in the classroom?

ii. How is CS manifested in the ESL classroom?

The first question is answered using an interview research design, while the second question is answered using an ethnographic recording research design.

\section{The Formation of Malaysian Chinese Independent Schools: A Brief Dossier}

Chinese educational institutions in Malaya were established in the early nineteenth century by Chinese settlers. This was done to provide their children with an opportunity to learn their mother tongue languages or dialects. According to $\mathrm{Ku}$ (2003), Chinese Education in Malaysia was developed to disseminate Chinese traditional values and to simultaneously instils the spirit of nationalism and political awareness to students. However, the Chinese schools at that time were a component of the vernacular education which were largely ignored by the British government (Thock, 2013, p. 19).

Over time, Chinese educational institutions were seen as troublesome nests of 'Chinese nationalists', and there were concerns that they could be instrumental in spreading political sedition (Loh, 1975). Compounding this issue for the colonial masters was the May Fourth Movement that spread anti-colonialism and democratic ideas. Not surprisingly, the Chinese education movement in the 1920s encountered opposition from the English colonial government. In two occasions, the Assistant Director of Education in the Straits Settlements in 1924 and the Federated Malay States in 1931 tried to increase supervision activities of Chinese schools (Xia, Yang \& Lee, 2018). This, however, did not stop further establishments of Chinese institutions in Peninsular Malaya. With the financial assistance of wealthy Chinese tycoons, Chinese schools grew from 252 in 1921 to 1,015. This growth was interrupted by the Japanese occupation of Malaya during World War II.

When the British regained administrative control of Malaya in 1945, the locals did not receive them with open arms. There was also a great distrust towards the Chinese as the war 
reminded the populace of ethnic groups affiliations, of those who supported the Imperial Japanese soldiers and Communism. To unite the nation, the 1951 Barnes Report aimed to nationalise all vernacular schools, to make Malay and English the bilingual instructions, and to maintain the English language in auxiliary schools. This was challenged by the Chinese, who wanted to use their mother-tongue for education. In 1951, the United Chinese School Teachers' Association of Malaysia (UCSTAM), or 'Jiao Zong', was established in response to the Barnes Report of 1951 to push for mother-tongue education. Soon after Malaysia got its independence, Chinese schools were rebranded as Malaysian Chinese Independent Schools (MCIS).

The subsequent 1960 Rahman Talib Report and the 1961 Education Act viewed MCIS as a 'threat'. There was increasing pressure to convert MCISs to national medium schools in return for state financing, and they were only allowed to conduct one-third of the school syllabus in Chinese. Seventeen MCIS declined to conform to the arrangement (cited in Low, 2016) and continued utilising Mandarin as the medium of instruction.

Under the supervision of Dong Jiao Zong to preserve, impart, and disseminate the Chinese language and its culture, Chinese education streams have resisted government attempts to assimilate into the national schools. Malaysia, to date, has become one of the few nations in the world that has a comprehensive Chinese language education, alongside China and Taiwan, Hong Kong, and Australia. Malaysia has a Chinese school system from elementary to advanced, forming a complete Chinese education system ( $\mathrm{Xu} \& \mathrm{Xu}, 2016)$. The 'three-three' education framework is used, with three years of junior secondary school and another three years of senior secondary school, similar to the school system practised in China and Taiwan. Each level often takes less than a year, and students who fail their exams may be retained in the same level. Mandarin is the main medium of instruction, with English and Malay being emphasised as well (Tay, 2007).

These schools execute a dual-track curriculum, in which MCIS education modules are taught as the principal course, while the government public examination preparation is taught as an accompaniment. The junior-middle 3 and senior-middle 2 students are required to sit for the Unified Examination Certificate (UEC) examination. Additionally, they are required to sit for the Pentaksiran Tingkatan 3 (PT3) and Sijil Pelajaran Malaysia (SPM) examinations. MCIS have come a long way in displaying a strong sense of cultural separateness on the issue of the national language and educational policies. 


\section{Code-switching, Teachers' Practices and Perception in the Classroom}

The term 'codes' often means 'speech varieties' (Wardhaugh, 2010, p. 164), and they refer to the use of different languages and registers. In this research, code-switching is understood as the switch between two spoken languages - Standard English and Standard Mandarin, as these are the registers used by the interlocutors in the recorded data. Studies show that CS in English as a Second Language (ESL) classrooms can have desirable academic outcomes. Teachers can employ CS to break the language barrier and assist students whenever students face difficulty by relating topics to the students' culture, or even to address behavioural problems (Lin, 2007). In the classroom, teachers can also collaborate with their students using CS (Canagarajah, 2011). Indeed, Rahman (2013)'s investigation in an ESL classroom in Assam reveals 65\% of his teacher participants employing CS to explain concepts and ideas to learners. The use of CS facilitates and supports students in English language learning. Likewise, Simasiku et al. (2015) show that CS helps students in mastering content subjects. In another study of CS, Yildiz and Yeşilyurt's (2017) Turkish participants advocate the use of Turkish in English classes. Turkish, as the students' mother tongue is helpful in explaining new words, giving instructions, explaining grammatical structures, checking to understand, providing feedback, joking and discussing classroom activities with students, and testing.

Rolin-Ianziti and Brownlie (2002) show that CS can also have three main purposes: translation, metalinguistic uses and communicative uses. Teachers can use CS to display convergence and solidarity with their students. For instance, teachers may switch to L1 as a signal of group membership and shared ethnicity with their students (see Chowdhury, 2012; Holmes, 2013; Barnes, 2012; Xiaofang, 2017). CS from English to the students' mother tongue can be used to tell jokes, talk about personal experiences, persuade others, and share ideas. Sert (2005) proposed that CS creates etymological solidarity, particularly between individuals who share the same ethnocultural personality. Comparably, Crystal (2002) states that a speaker's change from the majority dialect to the minority communicates solidarity with the minority group and builds compatibility with the recipient.

Perception is defined as a reflection of a person to any stimulus from the outside. To form perception, a person must first acknowledge and comprehend a certain event, and then an individual would make a judgment and consequently react to it (Clopper et. al.,2013). In this article, perception is referred to the teachers' knowledge of teaching and learning in dealing with 
CS in the classroom. Numerous studies have discovered the correlation between perception of CS and language practice in the second language classroom (Selamat, 2014; Leoanak \& Amalo, 2018; Lit et al., 2014). For instance, Selamat (2014), who focused her study on two Malaysian secondary schools, discovered the presence of perception on her participants' towards the use of CS in the classroom. The result, based on the context of the study, the teacher considered CS as a valuable teaching and learning resource. Hence, the use of CS corresponds to actual CS practices. Likewise, Leoanak and Amalo (2018) discovered that teachers in Indonesia perceive CS a positive strategy. It enables them to facilitate teaching and to achieve lesson objectives. Liu et al. (2014) who studied thirteen secondary schools in Korea found that teachers who did not regard the English subject as being important used approximately less than $25 \%$ of the time in class as compared to those who did.

\section{Research Methods}

This research was carried out in Chong Hwa Independent High School, one of the largest MCIS in Kuala Lumpur with the demography of approximately 5,300 students and 400 staff members. Each class has between 50 and 60 students. The students are generally Chinese, and it is the norm to hear Mandarin as the lingua franca. The school employs a 'three-three' education framework, where the students go through three years of junior and three years of senior secondary school before receiving a diploma upon completion. A grade-retention system was carried out for those who fail to acquire an average score of 60 per cent in a year. Moreover, the school manages and groups students according to their previous academic performance.

English is an obligatory subject in the school. Junior and intermediate students attend six English classes a week, while senior students have to attend eight classes a week. Each class is 40 minutes long. The EFL educators are from diverse academic backgrounds with teaching experiences that range from a few months to 35 years. At the time of study, there were English language teachers did not have English instructional training certificates, such as the Certificate in Teaching English to Speaker of Other Languages (CELTA), Teaching English as a Second Language (TESL), or Teaching English as a Foreign Language (TEFL).

The University of Malaya Research Ethics Committee Office approved the data collection methods of this research, and consent was obtained from the Principal of the school and the teachers. The teachers' profiles are as follows: 
Table 1: Background of the Participants

\begin{tabular}{|c|c|c|c|c|c|}
\hline \multirow[t]{2}{*}{$\begin{array}{l}\text { Teacher } \\
\text { (T) }\end{array}$} & \multirow{2}{*}{$\begin{array}{l}\text { Teacher } \\
\text { Highest } \\
\text { Academic } \\
\text { Background }\end{array}$} & \multirow[t]{2}{*}{$\begin{array}{l}\text { Native } \\
\text { Language }\end{array}$} & \multirow{2}{*}{$\begin{array}{l}\text { Teachers' } \\
\text { Teaching } \\
\text { Experience }\end{array}$} & \multicolumn{2}{|c|}{$\begin{array}{l}\text { Know about the term } \\
\text { 'code-switching' }\end{array}$} \\
\hline & & & & YES & NO \\
\hline 1 & Diploma & Chinese & 25 & $X$ & \\
\hline 2 & Masters & Chinese & 30 & & $\mathrm{X}$ \\
\hline 3 & Bachelor & Chinese & 2 & & $X$ \\
\hline 4 & Bachelor & Chinese & 3 & & $\mathrm{X}$ \\
\hline 5 & Bachelor & Chinese & 2 & & $X$ \\
\hline 6 & Bachelor & Chinese & 2 & & $\mathrm{X}$ \\
\hline 7 & Bachelor & Chinese & 2 & $X$ & \\
\hline
\end{tabular}

A total of 4.5 hours of classroom interactions and 14,744 words were recorded. As for the interview with the teachers, the length of the session varied, ranging from 10-20 minutes. The interview and classroom observation data were transcribed verbatim. The following methods were used to gather classroom interaction data: First, a naturalistic approach was employed to preserve the authenticity of the actual classroom speech. The teachers were provided with a recorder, and they switched it on before the lessons began to reduce the observer's paradox. Seven classroom recordings beginning from October 2017 to November 2017 were collected. After each recording, the class teacher was invited to participate in a one-on-one interview to answer Research Question 1. The interview is also audio-recorded and transcribed. The survey response is then analysed using Saldana (2015)'s first and second cycle coding. The first cycle of coding is the initial coding which aims to identify the comprehensible codes in the transcript. In the second cycle coding, the commonalities and grouping of the codes by similitudes are analysed. The following figure illustrates the analysis process. 


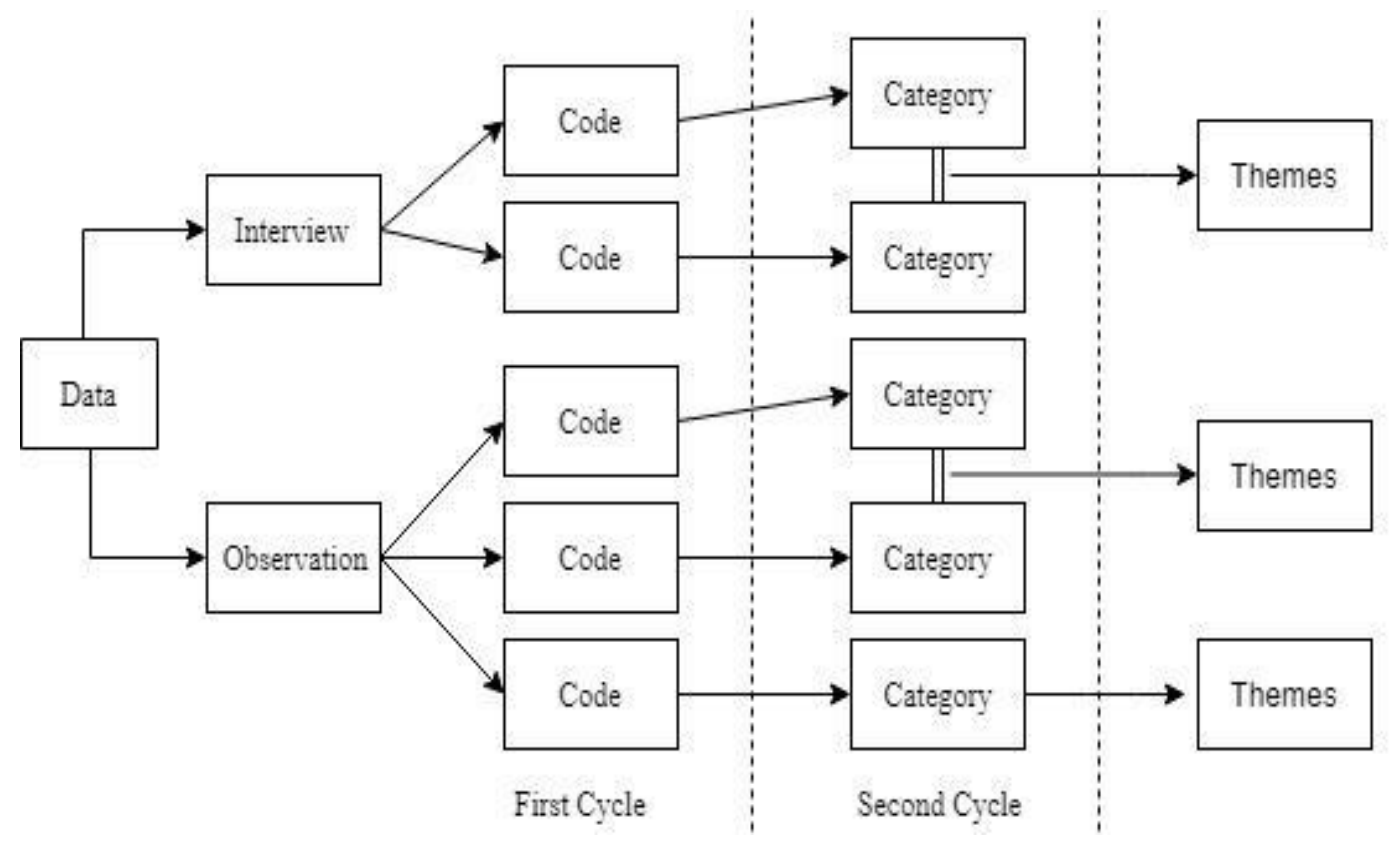

Figure 1: Procedure of Extracting Data for Analysis

\section{Results and Discussions}

The analysis revealed that all teachers, through classroom observations and transcription analysis, frequently used the Chinese language in their respective English language classrooms. However, one of the teachers (T6) utilised $80.5 \%$ of the Chinese in her English classroom. She says that her student prefers an instructor who speaks more Chinese in the English classroom. The recorded number of words the teachers CS in the classroom is as follows:

Table 2: Language use in the observed Classrooms

\begin{tabular}{|l|l|l|l|l|}
\hline Subject (T) & English & Chinese & Bahasa Malaysia & Total \\
\hline $\mathrm{T} 1$ & 2627 & 483 & 2 & 3112 \\
& $84.4 \%$ & $15.5 \%$ & $0.06 \%$ & $99.96 \%$ \\
\hline $\mathrm{T} 2$ & 830 & 745 & 1 & 1575 \\
& $52.7 \%$ & 47.3 & $0.06 \%$ & $100.06 \%$ \\
\hline $\mathrm{T} 3$ & 1523 & 846 & 0 & 2369 \\
& $64.3 \%$ & $35.7 \%$ & $0.00 \%$ & $100 \%$ \\
\hline
\end{tabular}




\begin{tabular}{|l|l|l|l|l|}
\hline T4 & $\begin{array}{l}1225 \\
94.3 \%\end{array}$ & $\begin{array}{l}74 \\
5.7 \%\end{array}$ & $\begin{array}{l}1 \\
0.08 \%\end{array}$ & $\begin{array}{l}1299 \\
100.8 \%\end{array}$ \\
\hline $\mathrm{T} 5$ & 1693 & 330 & 0 & 2023 \\
& $83.7 \%$ & $16.3 \%$ & $0.00 \%$ & $100 \%$ \\
\hline T6 & 304 & 1259 & 1 & 1564 \\
& $19.4 \%$ & $80.5 \%$ & $0.06 \%$ & $100 \%$ \\
\hline T7 & 2784 & 18 & 0 & 2802 \\
& $99.4 \%$ & $0.6 \%$ & $0.00 \%$ & $100 \%$ \\
\hline Total & $\mathbf{1 0 9 8 6}$ & $\mathbf{3 7 5 5}$ & $\mathbf{5}$ & $\mathbf{1 4 7 4 4}$ \\
& $\mathbf{( 7 4 . 5 \% )}$ & $\mathbf{( 3 4 . 2 \% )}$ & $\mathbf{( 0 . 0 3 \% )}$ & \\
\hline
\end{tabular}

The collected data show how CS is a conscious strategy for teachers to enrich their classroom learning environment. Among the emergent themes are as follows:

- Code-switching to facilitate learning (Section 5.1)

- Code-switching to compensate for students' language deficit (Section 5.2)

- Code-switching to express personal opinions (Section 5.3)

- Code-switching to establishing rapport (Section 5.4)

- Code-switching to accommodate students' attitude toward language learning (Section 5.5)

\subsection{CS to Facilitate Learning}

The teachers believe that CS aids learning. When asked about the perception of CS in the classroom, all teachers explain that CS is 'essential' and 'unavoidable'. This finding resonates with other literature in CS (Sert, 2005; Moradkhani, 2012; Leoanak \& Amalo, 2018). Among the practical use of CS found in the present study are translating (Moradkhani, 2012; Pan \& Pan, 2012) and checking meaning and grammar (Cook, 2001).

Similarly, Lin (2008) states that translation is fundamental for students to apply what they have learned before. In the example below, T4 \& T5 performed direct translations of the lexical items ‘吉祥物' (mascot) and '无可否认的' (undeniably) to assist students recognise the meaning of the words in the lesson. Meanwhile, T2 chose first to translate the term '前辈' because Chinese kinship practices are associated with other ideas like filial piety, family loyalty and the continuity of family lineage. The comparison of lexical items brings lessons closer to the students' culture 
and raises an "awareness of the similarities and differences between the two languages" (Chellappan, 1991).

Excerpt 1: CS to provide equivalent meaning

\begin{tabular}{|l|l|l|}
\hline Translation & T2 & $\begin{array}{l}\text { In this modern era, it is easy to lose tie with the tradition from our } \\
\text { forefathers...fore father 是前人前辈 ei 什么意思 ? 在这摩登时 } \\
\text { 代, 我们很容易呢跟我们的先主们失去接触 (is fore-father ei } \\
\text { what's the meaning? In this modern era, we are easily to lose tie with } \\
\text { our forefather }\end{array}$ \\
\cline { 2 - 3 } & T4 & Mascot, 吉祥物 (Mascot) \\
\cline { 2 - 3 } & T5 & undeniably, 无可否认的 (undeniably) \\
\hline
\end{tabular}

The data also show that teachers resort to CS to check meaning and grammar. The teachers frequently ask questions in the Chinese language to check on students' comprehension. According to Cotton (2001), questions can be used to evaluate students' understanding. Questions as shown in the following excerpts can also be used as a tool for teachers to determine if students are ready to move to another stage in the lesson.

Excerpt 2: CS questions to check comprehension

\begin{tabular}{|c|c|}
\hline T4: & 那 (then) people 加 (added with) $\mathrm{S}$ 是什么意思 (what meaning)? \\
\hline $\mathrm{S}:$ & Peoples \\
\hline T4: & Then... When do we use peoples? \\
\hline S: & (0.7) many people? (.) 就是很多很多人的时候 (when there are many people?) \\
\hline T4: & $\begin{array}{l}\text { Are you sure? person 是一个人 (is one person), people 是两个以上 (is two and } \\
\text { above), peoples 是你要表达同一个区域一个以上的民族团体 (is when you } \\
\text { express more than one ethic group in one region) }\end{array}$ \\
\hline
\end{tabular}


Excerpt 3: CS questions to check comprehension

\begin{tabular}{|l|l|}
\hline T5: & $\begin{array}{l}\text { Aisyah received an offer letter 入取通知书 (offer letter) from Cambridge } \\
\text { University. 收到了哪里来的信件? (where does the letter from?) }\end{array}$ \\
\hline S: & Cambridge 的 \\
\hline T5: & Ya... 对 (correct), Cambridge 的 (particle) 通知书 (offer letter) \\
\hline
\end{tabular}

Excerpt 4: CS questions to check comprehension

\begin{tabular}{|l|l|}
\hline T1: & What is crane? \\
\hline S: & 鹤 (crane) \\
\hline T1: & yes 鹤, 什么颜色的? Yes, (crane, what is the colour?) \\
\hline S: & 白色 (white) \\
\hline T1: & 白色 (white) \\
\hline
\end{tabular}

In Excerpt 2, T4 tries to explain the use of 'people' in the singular and plural forms. The teachers switched the '加' to check the students' comprehension. When the student is not able to answer the question correctly, the teacher switches to Chinese. Similarly, in Excerpt 3, the teacher (T5) translates 'official letter' “入取通知书” as a way of subtitling to help weaker students understand the text. Meanwhile, Excerpt 4 is an elaboration on the word 'crane'. The teacher begins by asking students what the word 'crane' means, and then asking the colour of the crane. The teachers employ $\mathrm{CS}$ in these questions to engage and assess their students' understanding.

\subsection{CS to Compensate for Students' Language Deficit}

In the ESL classroom, the teachers who are proficient English users often refrain from using English exclusively in the classroom. Such restraint stems from the consideration of students who 
are not quite competent in English. As mentioned earlier, teachers tend to switch to Mandarin because it is a language that is understood by the students. When asked, the teachers explain:

Excerpt 5: CS to compensate language deficits

If you speak mainly in English, some of them will not listen, just like when you want to scold them, or you want to tell them something serious it's better to tell them in Chinese, so they will get the point.

Excerpt 6: CS to compensate language deficits

Sometimes I think it's very hard for me to just use English in the classroom, students are weak, if I just use, they will just shut down and not listening, and don't even want to speak.

Excerpt 7: CS to compensate language deficits

Basically, it's like I just felt that students would pay more attention and I felt like class is quieter if I use Chinese language in the classroom because they will pay more attention.

The teachers say that if they use mainly English in the classroom, their students will become disengaged, and it will make controlling the class more challenging, thus reducing classroom participation. As mentioned in previous studies, communicative divergence can create distance in intelligibility between interlocutors (David \& McLellan, 2011, p. 290) and such distance can be counter-intuitive in the classroom, if learning is the main objective. Students learn better and form healthier relationships with their instructors if their instructors are relatable. Similarly, T4 voiced out the difficulty of engaging the students when English is the sole language use in the classroom. Meanwhile, T6 noticed behaviour change in students when she switches her language. She found that her students displayed more attention when she does this. 
It has been observed that the teachers commonly use English as their choice of language when teaching English. Cook (2008, p. 181) stresses the importance of using the second language in the beginning because it may be difficult for students to use it if teachers spoke in the native language at the beginning of class. However, this study shows that teachers are quick to change the language to Chinese when students are not following or are not clear about the instructor's guidance. This is shown in the following example:

Excerpt 8: Accommodating to students' language needs

\begin{tabular}{|l|l|}
\hline T2: & Today we are going to go through this piece of exercise about information transfer. \\
& $\begin{array}{l}\text { So please open to this page, u should have it in your blue file. 有吗? 有人没有吗? } \\
\text { 全部都有? (Has it? Does anyone don't have this? Everyone has it?) }\end{array}$
\end{tabular}

Excerpt 9: Accommodating to students' language needs

\begin{tabular}{|c|c|}
\hline T1: & $\begin{array}{l}\text { We have three more sessions before we will step into the exam hall. First, I have to } \\
\text { revise with your certain grammar topic that I think you should know lah. We will go } \\
\text { over again one or two topics, one of them is the conditional tenses... }\end{array}$ \\
\hline S: & 老师要做什么? (What does teacher want us to do?) \\
\hline T1: & $\begin{array}{l}\text { 没有 (nothing), 做 (do) conditional tense, 我要跟你们讨论一下。(I want to } \\
\text { discuss with you all for a while) }\end{array}$ \\
\hline
\end{tabular}

Excerpt 8 illustrates T2 informing students about the lesson of the day in English. She changes her interaction when she finds out that students did not respond to her instruction after a long pause. Possibly, she tries to avoid her student from being disengaged in the classroom. Meanwhile, T1 also begins his lessons in English. However, when students make inquiry in Chinese, the teacher answers in Chinese. The teacher tries to minimise the difference between the students by switching the language to become like theirs. 


\subsection{CS to Express Personal Opinion}

Another notable discovery from the data is CS is used to express the teachers' opinions, thoughts, ideas and feelings. The following excerpt depicts teachers showing dissatisfaction towards students' behaviour in the classroom using CS.

Excerpt 10: CS to express feelings

\begin{tabular}{|l|l|} 
T1 & $\begin{array}{l}\text { Tit for tat is an eye for an eye, a brat.... shhh... eh, 我不要教了 (I don't want to } \\
\text { teach already) (silent) Brat is a child who is spoiled ...真的是 我不要教了 (Truly } \\
\text { is, I don't want to teach already) }\end{array}$ \\
\hline
\end{tabular}

Excerpt 11: CS to express feelings

\begin{tabular}{|l|l} 
T1 & Can do or not? Can? 很累啦 (so tired la) continue la next time, okay?
\end{tabular}

Excerpt 12: CS to express feelings

\begin{tabular}{|l|l|}
\hline T7 & Can I give this correct? \\
\hline S & Of course! \\
\hline T7 & $\begin{array}{l}\text { Who teaches you that you can do this for your paper? no correction tape then } \\
\text { what you should do is this.... have I told you before that you should not do this? }\end{array}$ \\
\hline S & $\begin{array}{l}\text { Yerr... why like this one? } \\
\text { T7 }\end{array}$ \\
\hline $\begin{array}{l}\text { Okay, class, I will not give in if I have told you. don't tell me that you want to fight } \\
\text { 过了, 我一定不会妥协。 (If I have told you, I would not compromise) }\end{array}$ \\
\hline
\end{tabular}

T1 in Excerpt 10 is trying to explain the idioms 'tit for tat' is 'an eye for an eye'. However, the students were not listening to him. He switches his language to Chinese to express his dissatisfaction. However, the first attempt was not successful, so the teacher switches once more by uttering '真的是’ (truly is). 
CS for T7 on the other hand, happened when the students tried to plea for better the examination marks with the teacher. She was interrupted several times too. She uses CS to express her authority. Another example from T1 illustrates the teacher feeling fed up, and he presents a rhetorical question of whether to continue the lesson or not. This resonates with Malik's (1994) study, where he asserted that tired or angry bilinguals tend to code-switch.

\subsection{CS to Establish Rapport}

Another notable finding in the study is the teacher's attempt to establish rapport with the students. Managing rapport can also include dealing with problematic students and reducing the social distance between them. One way that teachers establish rapport is to tell CS jokes. For instance:

Excerpt 13: CS to establish rapport

T1: $\quad$ Okay so let's look at the five questions on critical reading... shhh... those who are weak at critical reading, please 来 (come), 5 题罢了 (five questions only), 我 的要求不高 (my requirement is not high), 娶老婆要求要高还是嫁老公 (but marrying a wife or husband) Haha (S), what are your conditions ?

In addition to the classroom study, the teacher endorses this in the interview because they believe code-switching would help them to engage with their students better, hence create a more friendly learning environment to catch students' attention during the learning process, as shown in the following excerpt.

Excerpt 14: CS to establish rapport

Nelson Mandela once said, if you speak to their mother tongue, you speak to their heart. If you speak in their second language, you speak to their mind. So, having a second language in the classroom also helps in building rapport with the students. (T1) 
Excerpt 15: CS to establish rapport

if they feel like you know their language, you have a certain connection to them. They will feel more connected to you and they will be more accepting of you. Supposed to sometimes, some teachers, other races may find it difficult to control the classes, to teach the classes, because they use different languages.

(T3)

Excerpt 16: CS to establish rapport

I must say that because their mother tongue is in Chinese language, if I use it, it does help in building rapport, so students will pay more attention for example sometimes when I use an English statement, they would understand but when I translate using Chinese, they will give me response.

(T5)

T1 and T3 explain that using CS helps bridge the gap between teacher and students. Following Sert (2005), CS allows the teacher to build a bridge from known to unknown and thus is an essential element in language teaching when used effectively. Meanwhile, T5 talked about the ability of code-switching in enabling students to perform and respond to the teacher's question. Metila (2009) says CS helps to improve class participation by inducing a relaxed class atmosphere that allows students to perform much better.

\subsection{CS to Accommodate Students' Attitude towards Language Learning}

The reason why we have teachers in the first place is the need to assist students in acquiring knowledge for specific purposes. Therefore, students are the key person which affects teachers' choice of language in delivering the lesson. Such diversity and dynamic of linguistic means are found in the following excerpt: 
Excerpt 17: CS to facilitate learning

Supposed to sometimes, some teachers may find it difficult to control the classes, to teach the classes, because they use different language.

Excerpt 18: CS to facilitate learning

Students have complained to me that for several years when they were taught by non-Chinese speaking teachers or by teachers who would not use Chinese language their learning effectiveness was minimal.

(T2)

Excerpt 19: CS to facilitate learning

First, I heard, the feedback from the students that they prefer teacher who can speak Chinese $\cdots$

(T6)

Excerpt 20: CS to facilitate learning

I get feedback from the students is that 'teacher we cannot really understand, so can $\mathrm{u}$ translate. Of coz we will do that for our students, but I don't know how to say, this is a Chinese school, so the teacher really needs to like to communicate with students in mandarin sometimes. The students they don't dare to speak English if they think that their English is weak and so on, so it is useful and I think we need to do that instead of using English only. (T7)

T2, T3, and T6 provided feedback by comparing the situation in class with non-Chinese speaking teachers. T7 claims that her students struggled to comprehend specific topics. Based on the students' feedback, she says teachers continue their pattern of teaching by employing the Chinese language in the classroom. Meanwhile, T5, T7 and T8 stated that the characteristics of the school, which is a Chinese school, compelled the use of the Chinese language to help them and the students 
achieve desired yields. This is a win-win situation for some teachers. As Levine (2003) states, the year of instruction, the proficiency level of a target language, the level of motivation, and the frequency of strategies on L2 use all have a great role in learning English. In this sense, L1 use may yield positive results in teaching to students with low-level of proficiency or motivation, and continuous use of target language may increase their anxiety and thus lead them to develop a negative attitude towards the language.

\section{Conclusion}

This study provides insight into teaching practices and perception of CS through the investigation of classroom discourse and a semi-structured interview with the ESL teachers in MCIS. The analysis of the teachers' classroom discourse suggests that teachers using CS is a common phenomenon. It is a conscious move performed by the teacher in this institution, and it is perceived to be a contributing factor to their professional development as it shapes the way they deliver their lessons in the classroom. One fascinating finding is that while the Chinese language is the precept language shared by the teachers and students, the findings show that English is still the stamped language in the classroom.

CS is employed in both pedagogical and social function. The study corroborates all the previous study of CS in classroom discourse. Specifically, from the present study, the teachers widely use CS for translating, checking meaning and grammar. CS is a useful tool in transmitting the knowledge which already existed in the students' mother tongue language. One interesting finding in the present study is the teacher CS by first comparing the lexical item, which is closer to the students' culture. A possible explanation for the findings is that the teacher hopes to raise awareness of the similarities and differences between the two languages, which aid students in making sense of the whole sentence. Another notable finding is that the teacher also found employing both CS and questioning techniques to engage with the students when checking students' understanding of the text and grammar.

Contemporary studies often see CS as part of the translanguaging because both CS and translanguaging consist of similar features. These features comprise of more than one language in an interaction. CS is a switch between two different language systems and the competence of one language is commonly above another. Translanguaging, on the other hand, attempts to co-construct and strengthen both languages as it requires individual making meaning by engaging their 
'linguistic repository' and expand from that (Gracia \& Liwei, 2014). In a pedagogical setting, translanguaging is a planned strategy that enables students to make meaning and learn (Williams, 2002). In this study, all teachers do not perform translanguaging for pedagogical purposes. One inference that can be made from the present study is that the teachers' purpose is not to develop bilingualism but to provide an understanding to the students in the topic. Switches happen naturally, and the translation of Mandarin comes after what teachers say in English as a means of helping students to understand the text so that the teachers can move on with their lessons quickly.

Apart from the pedagogical use of CS in the classroom, the analysis reveals CS as a strategy to maintain teacher-student relationship in the English classroom. For instance, the present study discovered teacher uses CS to accommodate students' weak language proficiency. From here, we can see that the teachers who are proficient in English language abruptly change the language to learners' mother tongue when they realised students are not giving any response to the teacher. According to Esen (2016), speaker CS because they want to express themselves with a personal style or flavour. In this sense, the teacher employed CS to express their opinion towards students that misbehave in the classroom. Last but not least, it was noted by us that code-switch allow teachers to create a stress-free environment. As a result, rapport is established between the teacher and students when the students respond with a similar switch. CS can also elicit the students' laughter.

\section{References}

Ahmad, B. H., \& Jusoff, K. (2009). Teachers' Code-Switching in Classroom Instructions for Low English Proficient Learners. English Language Teaching, 2(2), 49-55.

Barnes, L. (2012). The role of code-switching in the creation of an outsider identity in the bilingual film. Communication, 38(3), 247-260.

Canagarajah, S., (2011). Code meshing in academic writing: Identifying teachable strategies of translanguaging. The Modern Language Journal, 95(3). 401-417.

Chellappan, K. (1991). The role of translation in learning English as a second language. International Journal of Translation, 3, 61-72.

Chong Hwa Independent High School. Retrieved 10, April, 2019, from http://www.chonghwakl.edu.my/\%E5\%8A\%9E\%E5\%AD\%A6\%E6\%96\%B9\%E9\%92\%88/

Chowdhury, N. (2012).Classroom code-switching of English language teachers at tertiary level: A Bangladeshi perspective. Stamford Journal of English, 7, 40-61. 
Clopper, C. G., Rohrbeck, K. L. \& Wagner, L. (2012). Perception of dialect variation by young adults with High-Functioning Autism. Journal of Autism and Developmental Disorders, 42, 740-54

Cook, V. (2001). Using the first language in the classroom. Canadian Modern Language Review, 57(3), 402-423.

Cook, V. (2008). Second language learning and language teaching (4th ed.). London: Hodder Education.

Cotton, K. (2001). Classroom questioning. The Schooling Practices that matter most. $\quad$ Portland: Northwest Regional Educational Laboratory.

Crystal, D. (2006) Language and the Internet (2nd edition). Cambridge: Cambridge University Press.

David, M.K. and McLellan, J. 2011. Code Shifting and Switching: A Lingua Franca in Multilingual Malaysia? Purnima Singh, Paul Bain, Leong Chan-Hoong, Girishwar Misra, Yohsuke Ohtsubo (eds.): In Identity, Multiculturalism and Changing Societies: Psychological, Group and Cultural Processes, 290-291. Asian Social Psychology Series Volume 8. United Kingdom. MacMillan.

Dumanig, F. P., \& David, M. K. (2011). Language Choice and Naming of Businesses as a Marketing Strategy: Focus on Malaysia and the Philippines. Language in India, 11(8).

Esen, S. (2016) Code Switching-Definition, Types and Examples, Retrieved in Feb. 2018. from:https://owlcation.com/humanities/Code-Switching-Definition-Types-and-Examples-ofCode-Switching.

Garcia \& Li Wei (2014). Translanguaging: Language, Bilingualism and Education. Basingstoke: Plagrave Macmillan, 119 -135.

Hei, K. C., \& David, M. K. (2015). Not Careless but Weak: Language Mixing of Malaysian Chinese in a Business Transaction. English Review: Journal of English Education, 3(2), 127-138.

Holmes, J. (2013). An introduction to sociolinguistics. New York: Longman.

How, S. Y., Heng, C. S., \& Abdullah, A. N. (2015). Language Vitality of Malaysian languages and its Relation to Identity. GEMA Online ${ }^{\circledR}$ Journal of Language Studies, 15(2).

Ku, H. T. (2003). Education and Identity: A Study on Chinese Secondary Education in Malaysia (19452000). Xiamen: Xiamen University Press.

Leoanak, S. P. P., \& Amalo, B. K. (2018). Teachers' Beliefs and Perceptions of Code Switching in English as Foreign Language Classroom. In SHS Web of Conferences (Vol. 42, p. 34). EDP Sciences.

Levine GS (2003). Student and instructor beliefs and attitudes about target language use, first language use, and anxiety: Report of a questionnaire study. Modern Lang. J., 87(3), 343-364.

Lin, A. M. (2008). Code- switching in the classroom: Research paradigms and approaches. Encyclopedia of language and education, 3464-3477. 
Liu,D., Ahn,G.S., Baek, K.S., \& Han, N.O. (2004). South Korean High School English Teachers' Codeswitching: Questions and challenges in the drive for maximal use of English in Teaching. Tesol Quarterly,38(4),605-638.

Loh, P. F. S. (1975). Seeds of separatism: Educational policy in Malaya, 1874-1940. Oxford: Oxford University Press.

Low, S. M. (2016). The Effectiveness of Classroom Code-switching in Malaysian Science Classrooms (Doctoral dissertation, University of Sheffield).

Malik, L. (1994). Sociolinguistics: A study of code-switching. Anmol Publications PVT. LTD.

Metila, R. A. (2009). Decoding the switch: The functions of codeswitching in the classroom. Education Quarterly, 67(1), 44-61.

Moradkhani, S. (2012). The typology of EFL teachers' code switching: A validation study. Journal of Teaching Language Skills, 31(3), 103-126.

Pan, Y. C., \& Pan, Y. C. (2012). The use of translation in the EFL classroom. Philippine ESL Journal, 9 , 4-23.

Rahman, N. S. (2013). Language Choice Insight into Code-switching on Facebook by Bangladeshi Users (Master's thesis).

Reyes, I. (2004). Functions of code switching in schoolchildren's conversations. Bilingual Research Journal, 28(1), 77-98.

Rolin-Ianziti, J., \& Brownlie, S. (2002). Teacher use of learners' native language in the foreign language classroom. Canadian Modern Language Review, 58(3), 402-426.

Saldaña, J. (2015). The coding manual for qualitative researchers. Sage.Thousand Oaks, CA: Sage Publications.

Selamat, J. T. (2014). Code Switching in the Malaysian ESL Classroom. Master of Arts Thesis. University of Otago.

Sert, O. (2005). The functions of code switching in ELT classrooms. The Internet TESL Journal, 11(8). Retrieved from http://iteslj.org/Articles/SertCodeSwitching.html

Simasiku, L., Kasanda, C., \& Smit, T. (2015). Barriers to Code Switching in English Second Language Medium Classrooms. International Journal of English Literature and Culture, 3, 7-13.

Tay, L.S. (2007) [马来西亚华文教育发展简史] (trans: A Brief History of Chinese Education in Malaysia). 外语教学与研究出版社.

Thock, K. P. (2013). Impact of Language Policy and Nation-Building in Ethnic Hegemonic State: Issues Challenging the Resilience of Malaysian Chinese Schools. Journal Of Chinese Literature And Culture, 1, 17-44.

Thomas, L., \& Wareing, S. (2000). Language, society and power: An introduction. London: Routledge. 
Wardhaugh, R. (2010). An Introduction to Sociolinguistics (6 ${ }^{\text {th }}$ Edition). UK: Wiley-Blackwell

Williams, C (2002) A Language gained: A Study of Language Immersion at 11-16 years of age. University of Wales, Bangor. Retrieved from https://www.bangor.ac.uk/education-and-humandevelopment/publications/Language Gained\%20.pdf

Xia, N., Yang, Y., \& Lee, Y. F. (2018). Chinese Education in Malaysia under Malaysian Ethnic Politics. J. Pol. \& L., 11, 23.

Xiaofang, Q. (2017). Pedagogic and Social Functions of University EFL Teachers' Classroom Codeswitching. International Journal of Language and Linguistics, 5(6), 179.

Xu, L. L., \& Xu, P. (2016). The Popularization of Chinese Language in Multilingual Environment-Based on the Analysis of Examples from Malaysia. Paper presented at the 2nd International Conference on Modern Education and Social Science (MESS 2016).

Yao, M. (2011). On attitudes to teachers' code-switching in EFL classes. World journal of English language, 1(1), 19.

Yildiz, M., \& Yesilyurt, S. (2017). Use or Avoid? The Perceptions of Prospective English Teachers in Turkey about L1 Use in English Classes. English Language Teaching, 10(1), 84-96.

\section{About the Authors}

Wong Yee Von is a lecturer at the University of Selangor. She graduated with a Master of English as Second Language from the University of Malaya.

Email: yeevonwong@gmail.com

David Yoong is a linguist at the University of Malaya who specialises in Discourse Analysis. Email: davidyoong@um.edu.my 